\title{
Community-based surveillance in internally displaced people's camps and urban settings during a complex emergency in Yemen in 2020
}

Manal Salem Omar Baaees ${ }^{1 *}$, Jeremias D. Naiene ${ }^{1}$, Ali Ahmed Al-Waleedi ${ }^{2}$, Nasreen Salem Bin-Azoon², Muhammad Fawad Khan ${ }^{1}$, Nuha Mahmoud ${ }^{1}$ and Altaf Musani ${ }^{1}$

\begin{abstract}
Background: The need for early identification of coronavirus disease (COVID-19) cases in communities was high in Yemen during the first wave of the COVID-19 epidemic because most cases presenting to health facilities were severe. Early detection of cases would allow early interventions to interrupt the transmission chains. This study aimed to describe the implementation of community-based surveillance (CBS) in in internally displaced people (IDP) camps and urban settings in Yemen from 15 April 2020 to 30 September 2020.

Methods: Following the Centers for Disease Control and Prevention guidance for evaluation of surveillance systems, we assessed the usefulness and acceptability of CBS. For acceptability, we calculated the proportion of trained volunteers who reported disease alerts. To assess the usefulness, we compared the alerts reported through the electronic diseases early warning system (eDEWS) with the alerts reported through CBS and described the response activities implemented.

Results: In Al-Mukalla City, 18\% (14/78) of the volunteers reported at least one alert. In IDP camps, 58\% (18/31) of volunteers reported at least one alert. In Al-Mukalla City, CBS detected 49 alerts of influenza-like illness, whereas health facilities detected 561 cases of COVID-19. In IDP camps, CBS detected 91 alerts of influenza-like illness, compared to 10 alerts detected through eDEWS. In IDP camps, CBS detected three other syndromes besides influenza-like illness (febrile illness outbreak suspicion, acute diarrhoea, and skin disease). In IDP camps, public health actions were implemented for each disease detected and no further cases were reported.

Conclusions: In Yemen, CBS was useful for detecting suspected outbreaks in IDP camps. CBS implementation did not yield expected results in general communities in urban areas in the early stage of the COVID-19 pandemic when little was known about the disease. In the urban setting, the system failed to detect suspected COVID-19 cases and other diseases despite the ongoing outbreaks reported through eDEWS. In Yemen, as in other countries, feasibility and acceptability studies should be conducted few months before CBS expansion in urban communities. The project should be expanded in IDP camps, by creating COVID-19 and other disease outbreak reporting sites.
\end{abstract}

Keywords: Community-based surveillance, IDP camps, Urban settings, COVID-19, Complex emergency, Yemen

\footnotetext{
* Correspondence: baaeesm@who.int

${ }^{1}$ World Health Organization, Sana'a, Yemen

Full list of author information is available at the end of the article
}

(c) The Author(s). 2021 Open Access This article is licensed under a Creative Commons Attribution 4.0 International License, which permits use, sharing, adaptation, distribution and reproduction in any medium or format, as long as you give appropriate credit to the original author(s) and the source, provide a link to the Creative Commons licence, and indicate if changes were made. The images or other third party material in this article are included in the article's Creative Commons licence, unless indicated otherwise in a credit line to the material. If material is not included in the article's Creative Commons licence and your intended use is not permitted by statutory regulation or exceeds the permitted use, you will need to obtain permission directly from the copyright holder. To view a copy of this licence, visit http://creativecommons.org/licenses/by/4.0/ The Creative Commons Public Domain Dedication waiver (http://creativecommons.org/publicdomain/zero/1.0/) applies to the data made available in this article, unless otherwise stated in a credit line to the data. 


\section{Background}

When the novel coronavirus disease (COVID-19) epidemic was confirmed in Yemen on 10 April 2020, the country had an insufficient number of trained rapid response teams (RRTs) to investigate the suspected cases because of concurrent disease outbreaks, including cholera, diphtheria, arboviral diseases and others $[1,2]$. One RRT was available in each district to cover more than 300,000 people, and most of the COVID-19 cases did not report to the health facilities $[1,3]$.

The surveillance system in Yemen is exclusively based on the electronic diseases early warning system (eDEWS), in which most health facilities are used as reporting sites for epidemic-prone diseases. Data from the health facilities are reported in real-time and visualized at all levels, allowing early detection of abnormal disease trends [3]. The rumours from the communities are detected by the governorate health office $(\mathrm{GHO})$ through information provided by general public, media, and others. After rumour detection, the GHO deploys RRTs for investigation and response $[1,4]$. RRTs are Ministry of Public Health and Population (MOPHP) staff supported by partners, each team comprising a physician, surveillance officer, laboratory technician, environmental health officer and a risk communication officer [1]. The initial response of the RRTs may include health promotion, chlorination of water, search and removal of mosquito breeding sites, and case management of mild cases, depending on the disease investigated [4]. The rumours investigated by RRTs are also reported through eDEWS and published in the weekly bulletins produced by the MOPHP.

More than 40,000 community volunteers recruited by national and international organizations were available in Yemen, and they mainly implemented health promotion activities [4]. These volunteers were also encouraged to report rumours of suspected outbreaks to the GHO to deploy RRTs [3].

Active community surveillance is more effective in identifying missed cases during a disease outbreak than passive surveillance, which is more useful before an outbreak [5-8]. Active community surveillance to detect missed epidemic-prone disease cases can be useful in Yemen, where $42 \%$ of the population require at least a 1-h drive to reach a hospital [9]. Event-based surveillance, including community-based surveillance (CBS) may allow the earliest detection of outbreaks, especially cases not reported to the health facilities [10].

Cases among internally displaced people (IDP) may easily be missed owing to limited access to health facilities for self-reporting [11, 12]. Because of the ongoing armed conflict and natural disasters in Yemen, around 172,386 IDPs were present in different governorates in the country from January to December 2020 [13].
Several approaches of CBS have been used in developing countries $[6,14,15]$. However, there is no specific standard approach for CBS implementation, although more than 79 unique surveillance systems have been described in developing countries over the years [16]. To increase the chances of detecting COVID-19 cases in communities in Yemen, an active CBS was performed by the community volunteers from MOPHP and partner organizations in urban communities, and in IDP camps. The active CBS was done through door-to-door visits targeting mainly people with influenza-like illness, unexplained cluster of diseases, and acute public health events. The general community health volunteers from urban area (GCHVs) and IDP community health volunteers (ICHVs) reported to their health facility focal points (HFFPs) the cases detected through active CBS. The HFFPs requested the RRTs deployment by the GHO when the cases met COVID-19 case definition, or cluster of cases or deaths. The cases not fulfilling the above-mentioned criteria were referred to the nearest health facilities for treatment without deployment of RRTs. Suspected COVID-19 cases in Yemen were defined as any person with influenza-like illness and history of travel or residence in affected areas in the past 14 days before the symptom onset or any case of severe influenza-like illness without a precise diagnosis. Confirmed cases were cases with polymerase chain reaction test positive for COVID-19 infection [1]. Herein, we describe the implementation of CBS in IDP camps and urban settings in Yemen from 15 April 2020 to 30 September 2020. To our knowledge, this is the first documentation of CBS implementation in Yemen, and it provided evidence at the national level. The challenges and lessons learned can be considered before further expanding the project in Yemen and other countries with similar contexts.

\section{Methods \\ Setting}

The Republic of Yemen is a country in the Arabian Peninsula that is subdivided into 23 governorates. The governorates in Yemen are further subdivided into 333 districts [17]. Among the governorates, CBS in IDP camps was piloted in Aden, Abyan, Lahj, and Taiz, while Hadramout piloted CBS in urban setting (Fig. 1) [17-19]. This paper describes the CBS pilot in Yemen in all the governorates and districts where it was implemented.

Al-Mukalla city district in Hadramout governorate was selected for CBS piloting to target the general population in urban settings as part of a public health response to the first case of COVID-19 in Yemen. Although the case was reported in As Shikhr district, most of the patient's contacts were in Al-Mukalla city. Among the 10 zones, 


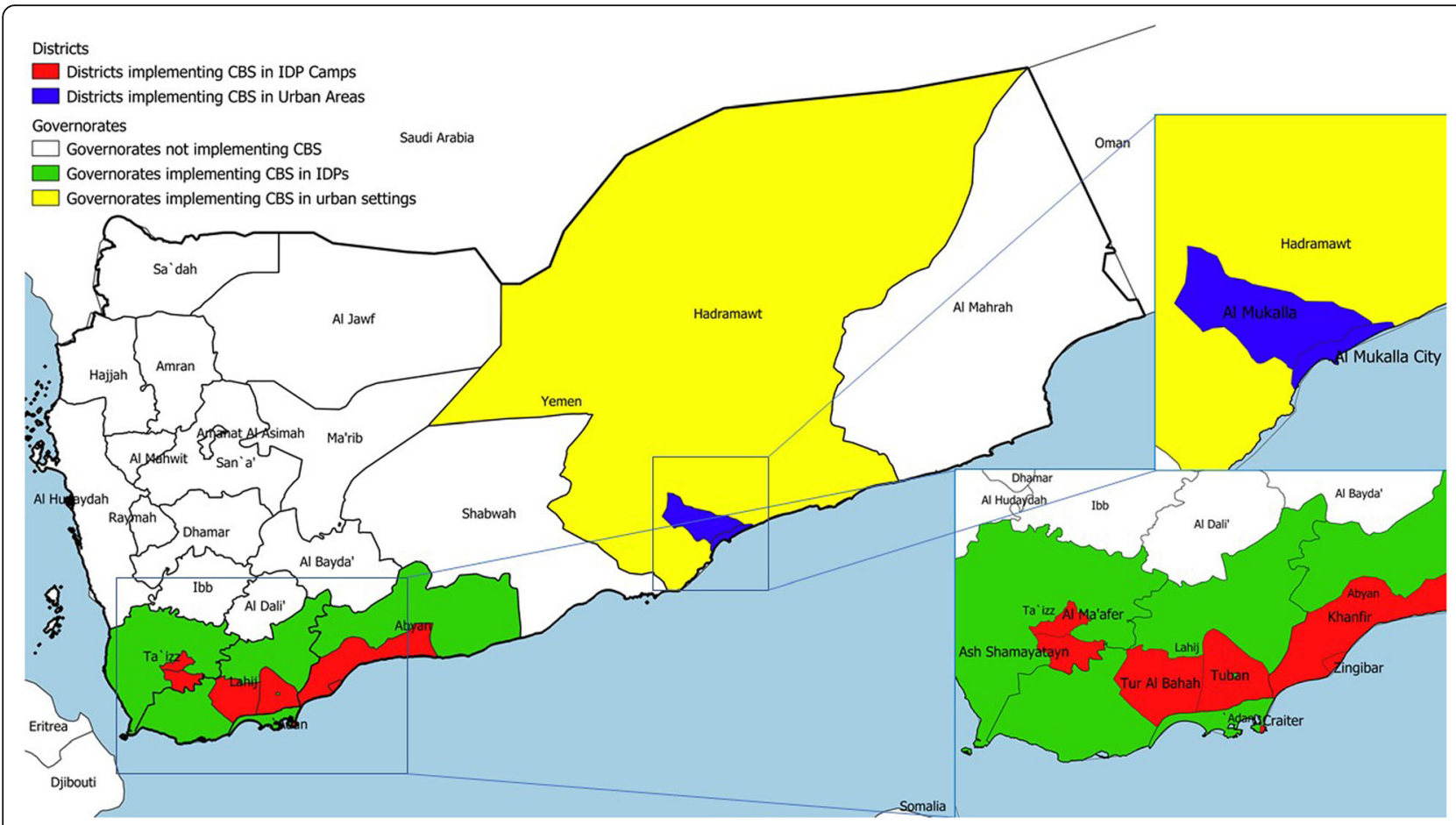

Fig. 1 Areas of implementation of community-based surveillance pilot in Yemen, 2020

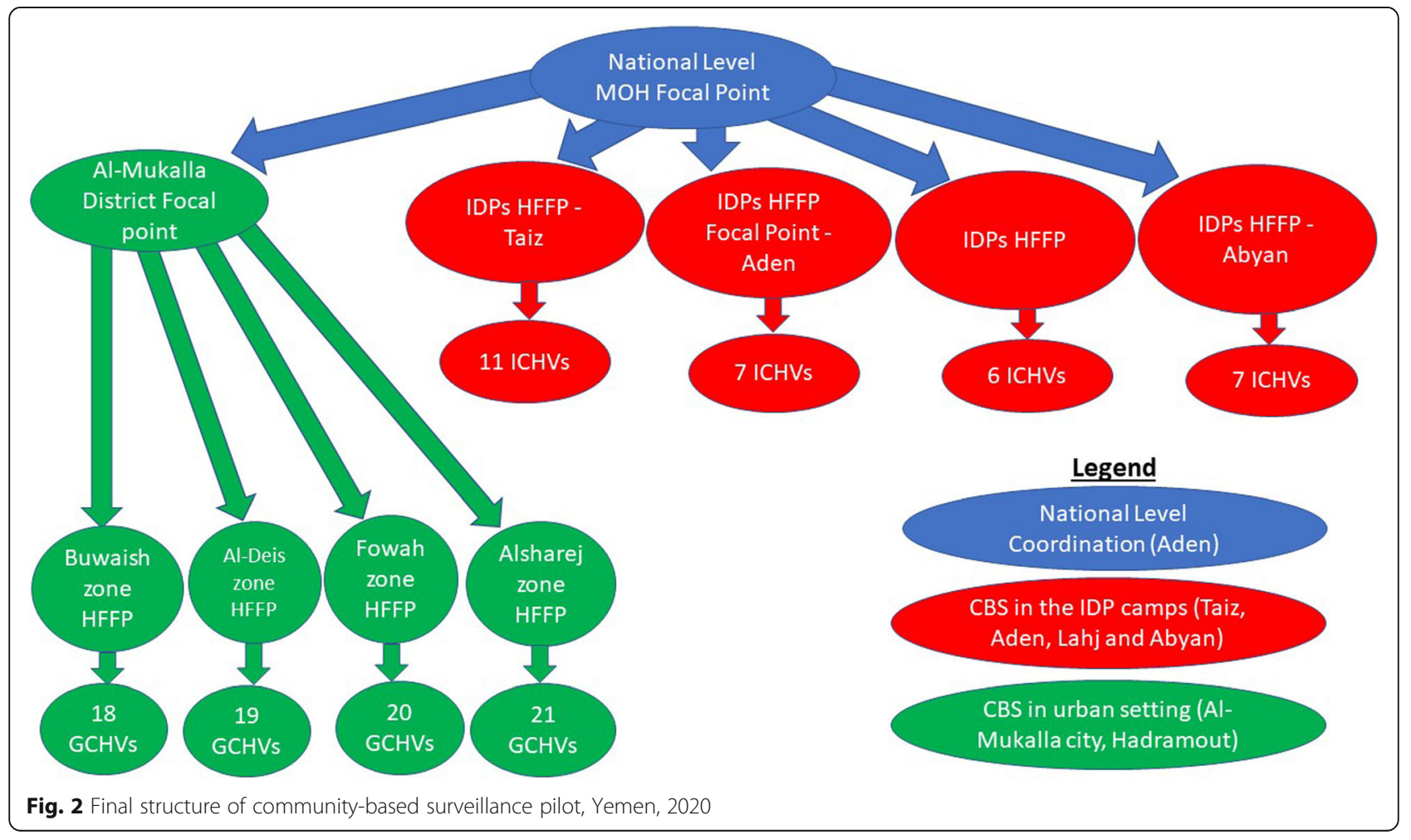


we performed CBS in four zones wherein the contacts of the index cases were located (Fig. 2).

Al-Mukalla city is an urban area and one of the 28 districts of Hadramout governorate, which has 10 zones [18]. In 2017, the total population in Al-Mukalla city was estimated to be 264,100 inhabitants projected from the 2004 census, with an average of 7 people per household $[18,20]$. The four zones selected for CBS pilot had a total population of 97,175 inhabitants (Table 1).

The CBS pilot targeting the IDP camps was performed in Aden, Lahj, Abyan, and Taizz because these governorates were accessible. Among the six governorates with the highest number of IDPs in Yemen, Marib, AlDhale'e, and Hudaydah were not easily accessible from Aden owing to ongoing armed conflicts. In each of the selected governorates, we selected the two districts with higher numbers of IDP camps and households, except Aden where IDP camps were concentrated in only one district, resulting in a total of seven districts selected for CBS (Table 2).

According to the International Organization for Migration (IOM)'s rapid displacement tracking (RDT) system, Marib, Al-Dhale'e, Taizz, Hudaydah, Lahj, and Abyan were the six governorates in Yemen with higher numbers of IDPs owing to active ongoing armed conflict. In the beginning of CBS project, on 15 April 2020, 71,304 IDP $(11,884$ households) were present in Yemen, and $14 \%$ of them were accommodated in tents, schools, and public buildings [13]. The others were welcomed by host families or rent houses in the general community. The seven districts that activated CBS had 32 IDP camps with a total population of 1806 inhabitants residing in the camps (Table 2).

\section{Alert triggers}

To make the CBS as simple as possible, while keeping it sensitive enough to detect suspected COVID-19 cases without missing other health-related problems in the community, the GCHVs and ICHVs were requested to report only two types of alerts. These include alerts of influenza-like illness and unexplained clusters of diseases or public health events. The standard case definitions were simplified into community case definition used as an alert trigger. The influenza-like illnesses community

Table 1 Trained volunteers in CBS in Hadramout, Yemen, 2020

\begin{tabular}{lll}
\hline Zone & Population & Number of volunteers \\
\hline Buwaish & 6177 & 18 \\
Fowa & 13,168 & 20 \\
Al-Deis & 33,226 & 19 \\
Alsharej & 44,604 & 21 \\
Total & 97,175 & 78 \\
\hline
\end{tabular}

CBS community-based surveillance case definition was "any case of acute onset of fever, cough, and difficult breathing". The community case definition for unexplained clusters of diseases or public health events was defined as "unknown community health problems affecting two or more people".

\section{Data source and analysis}

We examined the lists of focal points and volunteers provided by MOPHP and partners. We matched the abovementioned lists with attendance lists of the trainings to identify the number of people trained for CBS. Moreover, we examined all alert triggers, line lists, weekly narrative, weekly aggregated and training reports produced from 15 April 2020 to 30 September 2020. This report describes the selection process, including the number of volunteers selected, selection criteria, and distribution of households per volunteer. We also describe the training timeliness, topics covered, the number of people trained, active CBS and referral process, incentives and personal protective equipment (PPEs) provided, and reporting system. Summary statistics, including the number of cases, distribution by sex, age group, geographical location, epidemiological week, and proportion of severe cases, were calculated. Data in the line lists were compiled and analysed using Microsoft Excel. We manually extracted data of confirmed COVID-19 cases in Yemen from the daily reports available from the official twitter account of the MOPHP. Weekly narrative reports were produced by the HFFPs and highlighted in bullet points to their challenges and the volunteers under their supervisions. We also examined the Yemen eDEWS bulletins from week 19, 2020 to week 40, 2020 to extract the number of alerts detected through the system. The bulletins were publicly available on the Yemen Health Cluster website. The IDP demographic information was obtained from the dataset of the RDT system from 1 January 2020 to 4 July 2020, which was available publicly in the IOM website. From this dataset, we extracted the data of IDPs that were present when the first alert trigger was submitted by the ICHVs on 28 June 2020.

\section{Attributes of CBS system}

We followed the steps suggested in the World Health Organization (WHO) regional office for Africa guide for establishing a CBS in Yemen due to unavailability of specific guidelines for developing countries from the Eastern Mediterranean region [21]. We used the Centers for Disease Control and Prevention guidance for evaluation of surveillance systems to select the attributes of CBS presented in our report [22]. Based on the information collected during the CBS implementation in Yemen, we selected the attributes acceptability and usefulness. 
Table 2 Number of staff trained and CBS implementation in IDP camps by district in Yemen, 2020

\begin{tabular}{|c|c|c|c|c|c|c|c|c|c|}
\hline District & $\begin{array}{l}\text { Population } \\
\text { in IDP } \\
\text { camps }\end{array}$ & $\begin{array}{l}\text { Number } \\
\text { of IDP } \\
\text { camps }\end{array}$ & $\begin{array}{l}\text { Number of } \\
\text { IDP } \\
\text { households }^{\mathrm{a}}\end{array}$ & $\begin{array}{l}\text { Number of } \\
\text { IDP } \\
\text { households } \\
\text { in Camps }\end{array}$ & $\begin{array}{l}\text { Average } \\
\text { number of } \\
\text { households } \\
\text { per camp }\end{array}$ & $\begin{array}{l}\text { Number of } \\
\text { volunteers } \\
\text { trained }^{\mathrm{c}}\end{array}$ & $\begin{array}{l}\text { Number } \\
\text { of ICHVs } \\
\text { trained }\end{array}$ & $\begin{array}{l}\text { Number of } \\
\text { volunteers who } \\
\text { submitted at least } \\
\text { one report }^{d}\end{array}$ & $\begin{array}{l}\text { Status } \\
\text { of } \mathrm{CBS}^{\mathrm{e}}\end{array}$ \\
\hline & \multicolumn{9}{|c|}{ Taizz Governorate } \\
\hline $\begin{array}{l}\text { Ash- } \\
\text { Shamayatayn }\end{array}$ & 182 & 7 & 45 & 26 & 4 & 18 & 6 & 2 & Activated \\
\hline Al Ma'afer & 119 & 6 & 66 & 17 & 3 & 6 & 5 & 3 & Activated \\
\hline \multirow[t]{2}{*}{$\begin{array}{l}\text { Other } \\
\text { Districts }\end{array}$} & 490 & 12 & 1505 & 70 & 6 & 42 & 12 & 0 & $\begin{array}{l}\text { Not } \\
\text { Activated }\end{array}$ \\
\hline & \multicolumn{9}{|c|}{ Abyan Governorate } \\
\hline Zingibar & 210 & 2 & 139 & 30 & 15 & 2 & 2 & 1 & Activated \\
\hline Khanfir & 406 & 5 & 86 & 58 & 12 & 5 & 5 & 2 & Activated \\
\hline \multirow[t]{2}{*}{$\begin{array}{l}\text { Other } \\
\text { Districts }\end{array}$} & 119 & 4 & 702 & 17 & 4 & 11 & 11 & 0 & $\begin{array}{l}\text { Not } \\
\text { Activated }\end{array}$ \\
\hline & \multicolumn{9}{|c|}{ Lahj Governorate } \\
\hline Tuban & 84 & 5 & 23 & 12 & 2 & 5 & 4 & 3 & Activated \\
\hline Al Hawtah & 105 & 2 & 15 & 15 & 8 & 3 & 2 & 2 & Activated \\
\hline \multirow[t]{2}{*}{$\begin{array}{l}\text { Other } \\
\text { Districts }\end{array}$} & 140 & 0 & 795 & 20 & 0 & 11 & 0 & 0 & $\begin{array}{l}\text { Not } \\
\text { Activated }\end{array}$ \\
\hline & \multicolumn{9}{|c|}{ Aden Governorate } \\
\hline Craiter & 700 & 5 & 114 & 100 & 20 & 12 & 7 & 5 & Activated \\
\hline $\begin{array}{l}\text { Other } \\
\text { Districts }\end{array}$ & 28 & 2 & 131 & 4 & 2 & 15 & 5 & 0 & $\begin{array}{l}\text { Not } \\
\text { Activated }\end{array}$ \\
\hline
\end{tabular}

IDP internally displaced persons, CBS community-based surveillance, ICHV IDP camp community health volunteer

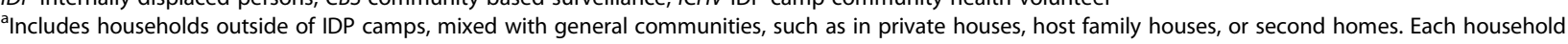
had an average of 7 people

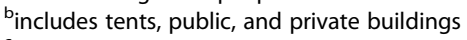

'The training also targeted volunteers to cover IDPs in the host communities and refugees, although they did not submit any report and CBS was not activated in those areas

${ }^{\mathrm{d} O n l y}$ ICHVs submitted reports, and not reports were submitted by the volunteers that were supposed to cover the IDPs in the host communities and refugees

e Despite the trainings targeting all the districts from the 4 governorates, only the 2 districts with a higher number of households were selected to activate CBS

\section{Acceptability}

We considered the acceptability of CBS as the willingness of the volunteers, health facility focal points, local authorities, organizations and the public to participate in the project [22]. To assess the acceptability, we calculated the proportion of ICHVs and GCHVs who submitted at least one alert trigger to the HFFPs. We also calculated the reporting rate of weekly aggregated reports, and weekly narrative reports submitted by the HFFPs to the governorate level. To estimate the number of weekly aggregated reports and weekly narrative reports that were expected to be submitted by the HFFPs, we multiplied the number of HFFPs by the number of weeks of CBS implementation. Therefore, the four HFFPs from IDP camps were expected to submit 52 weekly reports from the time of CBS activation in IDP camps on week 27, 2020 to the end of the project on week 40, 2020. The four HFFPs from Al-Mukalla City were expected to submit 84 weekly reports from the activation of CBS in an urban setting in week 19, 2020 to week 40, 2020.

\section{Usefulness}

We considered CBS useful if it satisfactorily detected suspected outbreaks and if the data collected led to the implementation of public health actions to control outbreaks [22]. To assess the ability of the CBS to detect outbreaks, we compared the number of alerts reported to the eDEWS with the alerts reported by ICHVs and GCHVs in the districts where CBS was activated. We also described the public health actions taken for cases detected by ICHVs and GCHVs to assess the usefulness of CBS. To understand the impact of public health actions, we counted the number of cases reported by the ICHVs and GCHVs after the actions were taken.

\section{Results}

\section{Key interventions}

Selection of CBS focal points and volunteers

Community volunteers previously conducting community for development (C4D) activities under the United Nations Children's Fund (UNICEF) were selected to perform CBS activities in urban setting. Community 
volunteers previously conducting health promotion activities under the Camp Coordination and Camp Management (CCCM) cluster partners were selected to perform CBS activities in IDP camps. The volunteers were previously conducting longstanding activities and they were selected to perform CBS activities in their area of residence. A total of 80 community volunteers supported by UNICEF were available and initially selected by the GHO from Hadramout to cover the four zones in Al-Mukalla City, namely Al Share, Al-Deis, Buwaish and Fowah zones, with 20 volunteers in each zone. According to the number of houses in the zones, each volunteer would cover 180 houses, each of them to be visited monthly. A total of 130 ICHVs were identified and selected by the CCCM cluster partners in coordination with the Executive Unit of IDPs, the governmental unit responsible for linking the government with the organizations supporting IDPs. This allowed each IDP camp to be covered by at least one ICHV, regardless of the number of households in the camp. Therefore, the number of households per ICHV ranged from 2 to 20 (Table 2). Any person able to read and write, aged more than 18 years, residing in the community or IDP camp and previously performing other health related tasks such as C4D or health promotion activities, was eligible to be GCHV or ICHV. The HFFPs from Al-Mukalla city were selected by the GHO from Hadramout, while the MOPHP national CBS coordinator selected the HFFPs from the IDP camps. Any person with epidemiological background was eligible for HFFP.

\section{Training of governorate, district, health facility and community level staff}

On 16 April 2020, the WHO conducted a one-day training of CBS in urban setting governorate level team trainers. The roll out training was conducted by the governorate focal point on 4 May 2020 and targeted district surveillance officers and HFFPs from Al-Mukalla city and three other districts in Hadramout governorate. From 27 to 29 April 2020, IDP camp HFFPs from Aden, Abyan, Lahj, and Taiz were trained. The ICHVs were trained from 4 to 6 May 2020 by HFFPs, and the GCHVs were trained from 6 to 8 May 2020 (Fig. 3). The training for both CBS in urban settings and IDP camps covered the basics of CBS, including key definitions, objectives, structure, roles and responsibilities, strategy, and others. The training also covered overview of respiratory illnesses, community case definitions, active CBS, reporting tools, and timeliness of notification and reporting. Brochures with health education messages and alert triggers were printed and distributed to all GCHVs, ICHVs and focal points.

A total of 14 district level staff from four districts were trained in CBS in Hadramout governorate. Additionally, 78 of 80 GCHVs selected in Al-Mukalla city district were trained, of whom $67 \%(n=52)$ were women $(\mathrm{Ta}$ bles 3 and 4). Moreover, 175 ICHVs were trained, of

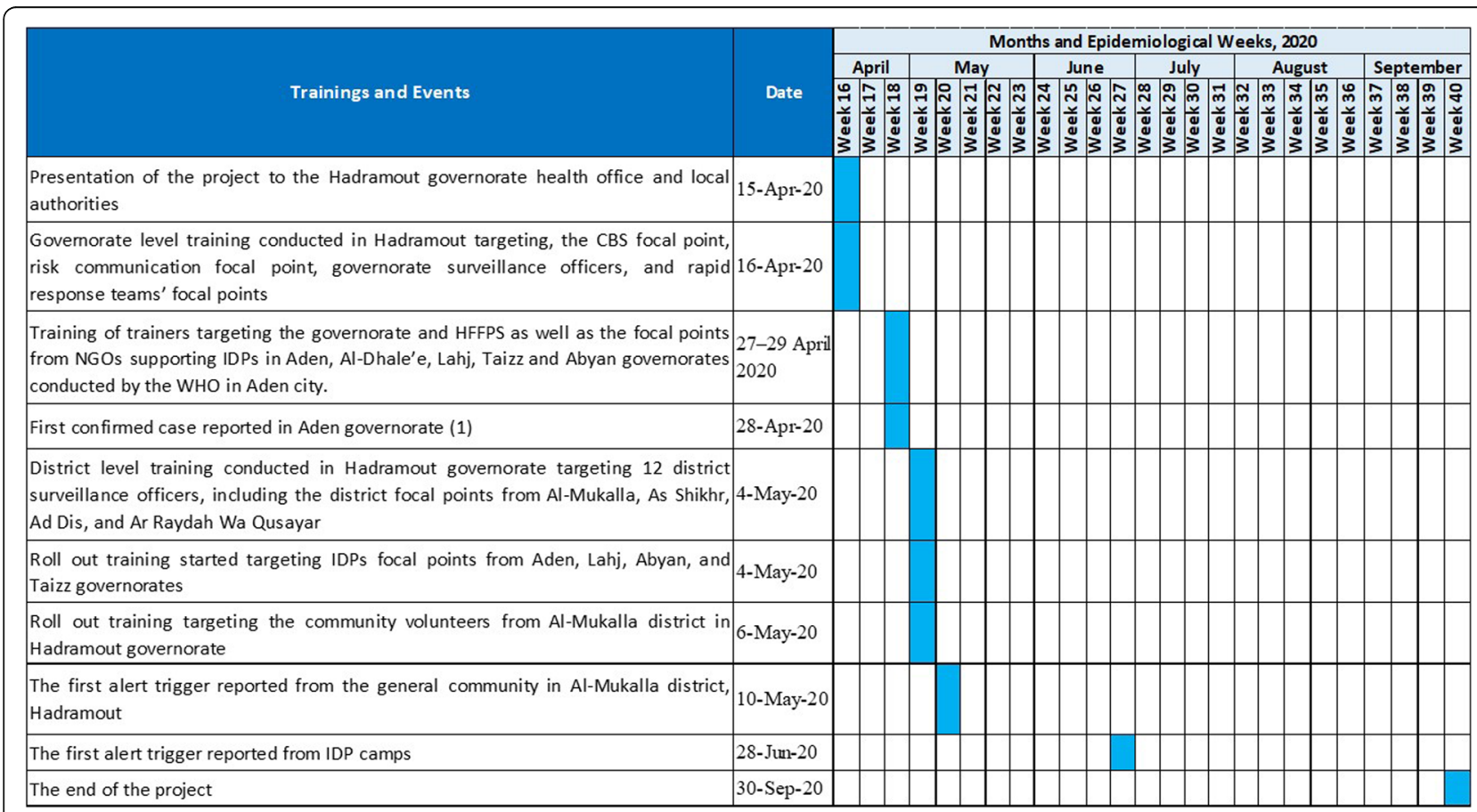

Fig. 3 Chronology of the main trainings and events related to CBS in Yemen, 2020 
Table 3 Distribution of the staff trained in CBS by district in Hadramout, Yemen, 2020

\begin{tabular}{|c|c|c|c|c|c|}
\hline & \multicolumn{4}{|l|}{ District } & \multirow[b]{2}{*}{ Total } \\
\hline & Al-Mukalla city & As Shikhr & Ad Dis & Ar Raydah Wa Qusayar & \\
\hline District surveillance officers trained in CBS & 1 & 1 & 1 & 1 & 4 \\
\hline Health facility focal points trained & 4 & 2 & 2 & 2 & 10 \\
\hline Community volunteers trained on $\mathrm{CBS}^{\mathrm{a}}$ & 78 & 0 & 0 & 0 & 78 \\
\hline Number of zones selected for CBS & 4 & 0 & 0 & 0 & 4 \\
\hline Hadramout governorate level surveillance officers trained in CBS & NA & NA & NA & NA & $6^{b}$ \\
\hline Status of CBS & Activated & Not Activated & Not Activated & Not Activated & \\
\hline
\end{tabular}

CBS community-based surveillance, NA not applicable

${ }^{a} 20$ volunteers trained for each zone, except two zones were 19 volunteers were trained in each

${ }^{b}$ Only includes the surveillance officers trained at the governorate level, excluding the ones trained at the district level

whom 31 were assigned to be ICHVs in areas where CBS was activated. Of the ICHVs trained, $74 \%(n=130)$ were men. All HFFPs selected for community surveillance in IDP camps were medical doctors, whereas those in Hadramout governorate were non-clinicians with basic training in public health surveillance.

\section{Organisation of CBS and referral}

GCHVs and ICHVs actively searched for suspected COVID-19 cases and unusual cluster of diseases in communities and IDP camps respectively through daily door-to-door visits and weekly community meetings. The GCHVs and ICHVs were requested to conduct weekly meetings with the communities to auscultate the main challenges faced by the communities and to detect cases missed during door-to-door visits. Moreover, the GCHVs and ICHVs performed health education activities during the door-to-door visits and community meetings. Transportation allowance was provided by the WHO to all trained GCHVs and ICHVs to facilitate their movement. The allowance for GCHVs and ICHVs was calculated based on the rate applied by MOPHP and the distance travelled. UNICEF and CCCM partners provided PPEs to the GCHVs and ICHVs respectively for the activities that they had previously performed before the CBS pilot, including C4D and health promotion activities. These PPEs included masks, gloves, face shields, and gowns. Further, they were also used for CBS activities as no additional PPE was available due to the global shortage. The GCHVs and ICHVs were oriented to follow all preventive measures, including physical distancing, always wearing PPEs while interacting with household members and not entering the houses.

\section{Data transmission and feedback}

Immediately after identifying suspected COVID-19 cases and the unusual cluster of diseases, the GCHVs and ICHVs were responsible for contacting the HFFPs through text messages or phone calls and filling in alert trigger forms with detailed information of the cases. The alert trigger form used by the GCHVs and ICHVs included the same information, namely the date of reporting, demographic information of the patient, duration of illness, main signs and symptoms and how the case was detected (see Additional file 1 and Additional file 2). The HFFPs assessed whether the cases required further investigation by RRTs, direct referral to a health facility, or home stay (Fig. 4). The assessment was done through phone calls to the volunteers and patients to obtain additional clinical information and classify the cases according to their severity and public health impact. Potentially severe cases were also visited physically after phone calls. A photo of the alert trigger form was also sent in real time to the HFFP via a WhatsApp message. The HFFP compiled the alert triggers variables in a line list and weekly aggregated form. The weekly aggregated form included the total number of cases, deaths, cases by age group, number of cases by disease, number of cases discovered through door-to-door visits, community meetings and others, and number of cases referred to RRTs, health facilities and advised to stay home (see Additional file 3). The line lists contained all the variables included in the alert trigger form, detailed signs and symptoms, case classification in mild, moderate, or severe, and actions taken for each case. The GCHVs, ICHVs and HFFPs were also requested to produce a weekly narrative report highlighting the main activities implemented during the week and challenges faced in bullet points. Credit for phone calls and internet was provided by WHO to the GCHVs, ICHVs and HFFPs. HFFPs provided feedback about the quality of the reports, accuracy of the alert triggers and findings of the initial assessment of the cases to the GCHVs and ICHVs during weekly coordination meetings.

\section{Reports submitted}

In Hadramout governorate, 18\% (14/78) of trained GCHVs submitted at least one alert trigger form to the HFFP (Table 5). Among trained ICHVs in districts selected for CBS implementation, 58\% (18/31) submitted 
Table 4 Demographic characteristics of staff trained in CBS in Yemen, 2020

\begin{tabular}{|c|c|c|c|c|c|c|c|c|c|c|c|}
\hline \multirow[t]{2}{*}{ Governorate } & \multirow[t]{2}{*}{ District } & \multirow{2}{*}{$\begin{array}{l}\text { Zone/ } \\
\text { Site }\end{array}$} & \multirow[t]{2}{*}{ Level } & \multirow[t]{2}{*}{ Function } & \multicolumn{3}{|c|}{ Gender } & \multicolumn{4}{|c|}{ Background } \\
\hline & & & & & Male & Female & Total & $\begin{array}{l}\text { Medical } \\
\text { Doctor }\end{array}$ & Nurse & Pharmacist & Others $^{2}$ \\
\hline Aden & NA & NA & National & $\begin{array}{l}\text { CBS } \\
\text { Coordinator }\end{array}$ & 0 & 1 & 1 & 1 & 0 & 0 & 0 \\
\hline \multicolumn{12}{|l|}{ General CBS } \\
\hline Hadramout & Al-Mukalla & NA & Governorate $^{b}$ & $\begin{array}{l}\text { CBS } \\
\text { Coordinator }\end{array}$ & 1 & 0 & 1 & 0 & 0 & 0 & 1 \\
\hline Hadramout & Al-Mukalla & Buwaish & Zone & HFFP & 1 & 0 & 1 & 0 & 1 & 0 & 0 \\
\hline Hadramout & Al-Mukalla & Al-Deis & Zone & HFFP & 1 & 0 & 1 & 0 & 0 & 1 & 0 \\
\hline Hadramout & Al-Mukalla & Fowa & Zone & HFFP & 0 & 1 & 1 & 0 & 1 & 0 & 1 \\
\hline Hadramout & Al-Mukalla & Alsharej & Zone & HFFP & 0 & 1 & 1 & 0 & 0 & 0 & 1 \\
\hline Hadramout & Al-Mukalla & Buwaish & Community & GCHV & 7 & 11 & 18 & 0 & 0 & 0 & 18 \\
\hline Hadramout & Al-Mukalla & Al-Deis & Community & GCHV & 10 & 9 & 19 & 0 & 0 & 0 & 19 \\
\hline Hadramout & Al-Mukalla & Fowa & Community & GCHV & 7 & 13 & 20 & 0 & 0 & 0 & 20 \\
\hline Hadramout & Al-Mukalla & Alsharej & Community & GCHV & 2 & 19 & 21 & 0 & 0 & 0 & 21 \\
\hline \multicolumn{12}{|c|}{ CBS in IDPs/Refugee sites } \\
\hline Aden & NA & NA & Governorate & HFFP & 1 & 0 & 0 & 1 & 0 & 0 & 0 \\
\hline Lahj & NA & NA & Governorate & HFFP & 1 & 0 & 0 & 1 & 0 & 0 & 0 \\
\hline Abyan & NA & NA & Governorate & HFFP & 1 & 0 & 0 & 1 & 0 & 0 & 0 \\
\hline Taizz & NA & NA & Governorate & HFFP & 1 & 0 & 0 & 1 & 0 & 0 & 0 \\
\hline Abyan & Zingibar and Khanfir & NA & IDP camp & $\mathrm{ICHV}$ & 14 & 4 & 18 & 0 & 0 & 0 & 18 \\
\hline Aden & Craiter & NA & IDP camp & $\mathrm{ICHV}$ & 18 & 9 & 27 & 0 & 0 & 0 & 27 \\
\hline Lahj & Tuban and Al Hawtah & NA & IDP camp & ICHV & 11 & 8 & 19 & 0 & 0 & 0 & 19 \\
\hline Al-Dhale'e & $\begin{array}{l}\text { Ad-Dhale, Qa'atabah, Al-Hussein, Al- } \\
\text { Azarik }\end{array}$ & NA & Community & $N A^{c}$ & 26 & 3 & 29 & 0 & 0 & 0 & 29 \\
\hline Hudaydah & Khokha, Tuhayta & NA & Community & $N A^{c}$ & 13 & 3 & 16 & 0 & 0 & 0 & 16 \\
\hline Taizz & Ash-Shamayatayn and Almaafer & NA & IDP camp & $\mathrm{ICHV}$ & 48 & 18 & 66 & 0 & 0 & 0 & 66 \\
\hline
\end{tabular}

NA not applicable, CBS community-based surveillance, IDP internally displaced person, GCHV general community health volunteer, HFFP health facility focal point, ICHV IDP camp community health volunteer

aParamedics, physician assistants, and non-clinicians (including a bachelor's degree in public health) with a formal training in public health surveillance

${ }^{b}$ Was in charge also for Al-Mukalla district because it was the only district activating CBS in the Hadramout governorate

'The volunteers were trained to work in CBS targeting the IDP in host communities outside of the camps, but CBS was not activated in this target groups

at least one alert trigger form (Table 2). The HFFPs from IDP camps submitted $100 \%$ of the expected 52 weekly aggregated reports and $10 \%(n=5)$ weekly narrative reports. The HFFPs from Al-Mukalla city submitted $65 \%$ $(n=55)$ of the expected 84 weekly aggregated reports and $1 \%(n=1)$ of weekly narrative reports.

\section{Alerts detected through CBS and eDEWS Overall alerts}

From 10 May 2020 to 24 September 2020, a total of 49 alerts were reported by the GCHVs, all of them influenza-like illnesses. The GCHVs reported no deaths during the same surveillance period. All cases in Hadramout governorate were detected during door-todoor visits and were referred to health facilities and the RRTs were not deployed. From 28 June 2020, when the first alert was reported in IDP camps, to 30 September 2020, 133 alerts were reported by the ICHVs, 69\% ( $n=$ 92) of them being the influenza-like illness and $31 \%(n=$ 41) being unexplained clusters of diseases or public health events. During the same surveillance period, six main groups of disease alerts, namely influenza-like, chronic respiratory, acute febrile illnesses, acute diarrhoea, skin disease, and abdominal distension, were detected by ICHVs (Fig. 5). The alerts of chronic respiratory illness and abdominal distention had no criteria to be reported by the ICHVs as they did not constitute a cluster of a disease involving two or more people.

\section{Influenza-like illness and COVID-19}

From the 49 alerts of influenza-like illness detected by GCHVs from 10 May 2020 to 24 September 2020, information about the severity of the cases, and cases making suspected COVID-19 case definition were not documented in the line list from Al-Mukalla city. The Buwaish district reported $49 \%$ of all cases and from all age groups (Table 6). During the same surveillance period, a total of 561 confirmed COVID-19 cases, including 224 deaths (case fatality ratio $=40 \%$ ) were detected by health facilities in Al-Mukalla city (Fig. 6). 


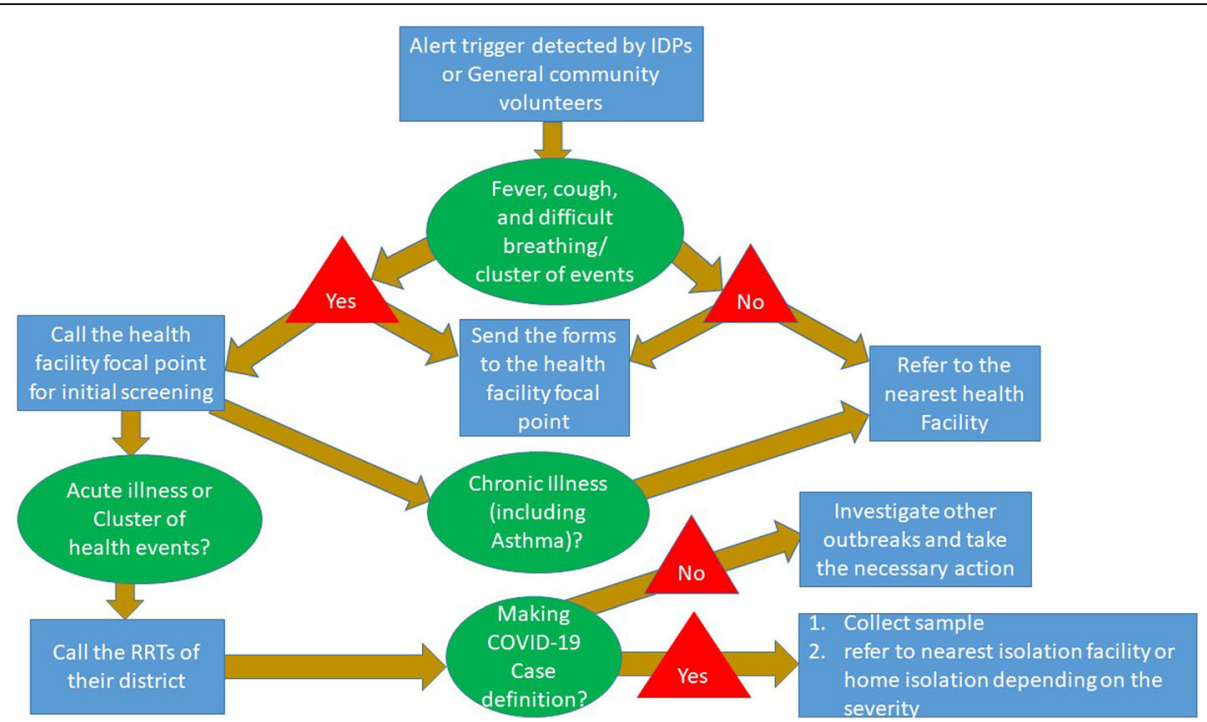

Fig. 4 Actions taken to alert triggers identified through community-based surveillance, Yemen, 2020

Influenza-like illnesses were the most reported alerts by ICHVs, with 92 cases and 0 deaths reported from 9 IDP camps and 5 districts in Aden, Lahj, and Taiz governorates (Fig. 7). None of them made suspected COVID19 case definition.

Among the 92 reported cases, 22\% $(n=20)$ were severe and $78 \%(n=72)$ were mild cases. Among the mild cases, $35 \%(n=25)$ were advised to receive care at home. Furthermore, among 92 reported cases, 73\% $(n=67)$, including all severe cases, were referred to health facilities. All cases of influenza-like illness were sporadic, and none of them was investigated by RRTs. During the implementation of CBS in IDP camps, 10 COVID-19 cases were detected by the health facilities from three districts implementing CBS: five cases in Craiter district in Aden governorate, two cases in Ash-Shamayatayn, and two cases in $\mathrm{Al} \mathrm{Ma}$ 'afer districts, both in Taiz governorate. None of the cases were referred from IDP camps.

\section{Unexplained cluster of diseases}

Although the GCHVs did not detect cluster of diseases or public health events besides influenza-like illness, 284 alerts of acute febrile illness were detected through eDEWS in Al-Mukalla city. The city was affected by a dengue fever outbreak. Alerts of suspected measles, pertussis, diphtheria, viral haemorrhagic fever and cholera were also detected through eDEWS during the surveillance period, each of them with less than 10 cases reported.

The ICHVs detected alerts of 25 cases and 1 death owing to acute febrile illness from 7 camps and 5 districts in Abyan, Aden, and Lahj governorates. All the cases were mild, barring a severe case reported in Lahj governorate, which ended in death. Furthermore, all cases were referred to health facilities for treatment. During week 32, one cluster of seven cases of acute febrile illness was detected in a camp in Abyan governorate, affecting children aged $<10$ years. The RRTs were called for investigation and response. All the cases were mild, with isolated fever, without other associated symptoms. Four cases were females, and 4 were children aged $<5$ years.

A cluster of six cases (no deaths) of acute diarrhoea was detected by ICHVs in a camp in Aden governorate during week 32 . All the cases were mild and were reported in four children aged $<5$ years and two adults of 28 and 35 years. The RRTs were called for investigation and response.

Table 5 Community report submission through CBS in Hadramout, Yemen, 2020

\begin{tabular}{lll}
\hline Zone & Number of volunteers who sent at least one alert trigger & Percentage of volunteers who sent alert triggers \\
\hline Buwaish & 2 & $11 \%$ \\
Fowa & 4 & $20 \%$ \\
Al-Deis & 6 & $32 \%$ \\
Alsharej & 2 & $10 \%$ \\
Total & 14 & $18 \%$ \\
\hline
\end{tabular}




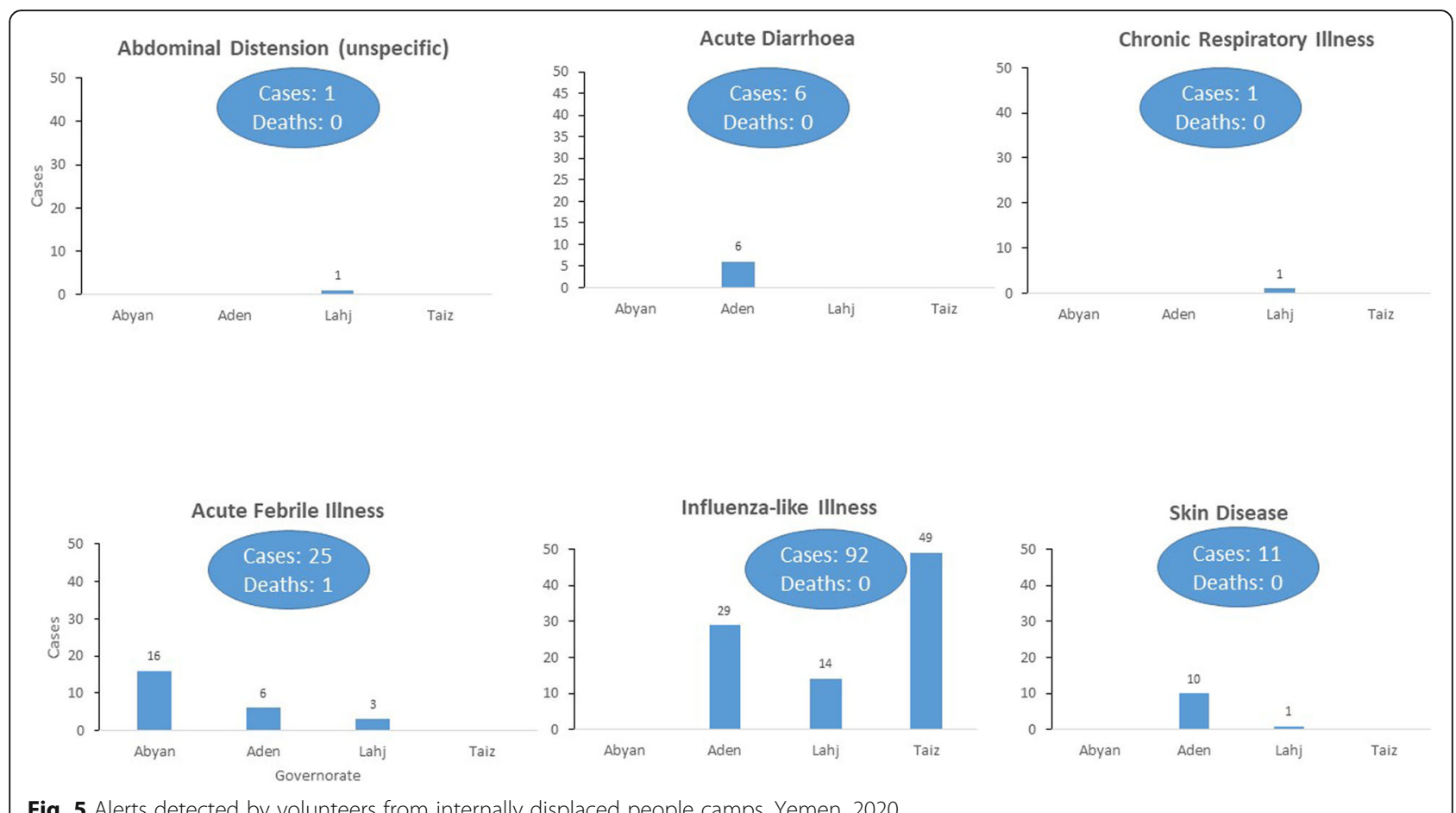

Fig. 5 Alerts detected by volunteers from internally displaced people camps, Yemen, 2020

During weeks 27 and 32, ICHVs also detected two cluster of a mild skin disease in two camps in Aden governorate. The RRTs were called for investigation and response to the two clusters. Each of the clusters affected five people, with $80 \%$ of them $(n=8)$ being children aged $<10$ years and the remaining being two adults of 18 and 35 years (Fig. 8).

All cases of diseases detected by ICHVs were detected through household visits, except two cases of acute febrile illness and one case of skin disease detected during community meetings. During the same surveillance period, all the districts implementing CBS in IDP camp were affected by dengue fever and cholera outbreaks. Those districts reported a total of 334 alerts of acute febrile illness, 188 alerts of acute watery diarrhoea, 12 alerts of pertussis and 10 alerts of influenza-like illness through eDEWS during the period of CBS implementation. No alert of skin disease alerts were reported through the eDEWS.

Table 6 Cases of influenza-like illness reported through CBS in Hadramout, Yemen, 2020

\begin{tabular}{|c|c|c|c|c|c|}
\hline & Al Share zone & Al-Deis zone & Buwaish zone & Fowah zone & Total \\
\hline \multicolumn{6}{|l|}{ Sex } \\
\hline Female & 4 & 2 & 6 & 0 & 12 \\
\hline Male & 10 & 4 & 18 & 5 & 37 \\
\hline Total & 14 & 6 & 24 & 5 & 49 \\
\hline \multicolumn{6}{|c|}{ Age group, years } \\
\hline $0-4$ & 2 & 0 & 1 & 0 & 3 \\
\hline $5-9$ & 1 & 1 & 4 & 1 & 7 \\
\hline 10-19 & 3 & 2 & 3 & 0 & 8 \\
\hline $20-29$ & 1 & 1 & 4 & 0 & 6 \\
\hline $30-39$ & 3 & 2 & 3 & 0 & 8 \\
\hline $40-49$ & 2 & 0 & 1 & 1 & 4 \\
\hline $50-59$ & 2 & 0 & 4 & 2 & 8 \\
\hline$>60$ & 0 & 0 & 4 & 1 & 5 \\
\hline
\end{tabular}



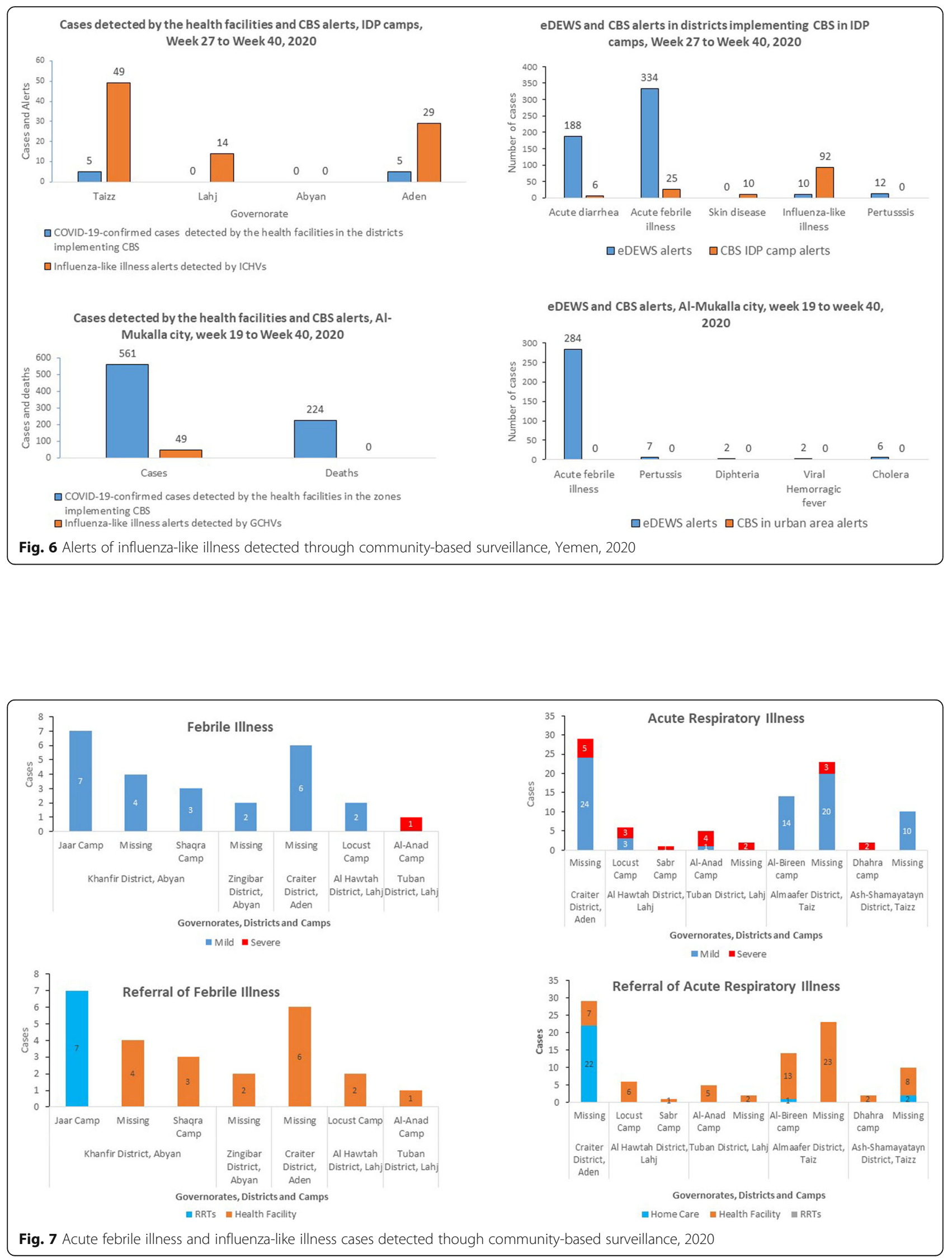


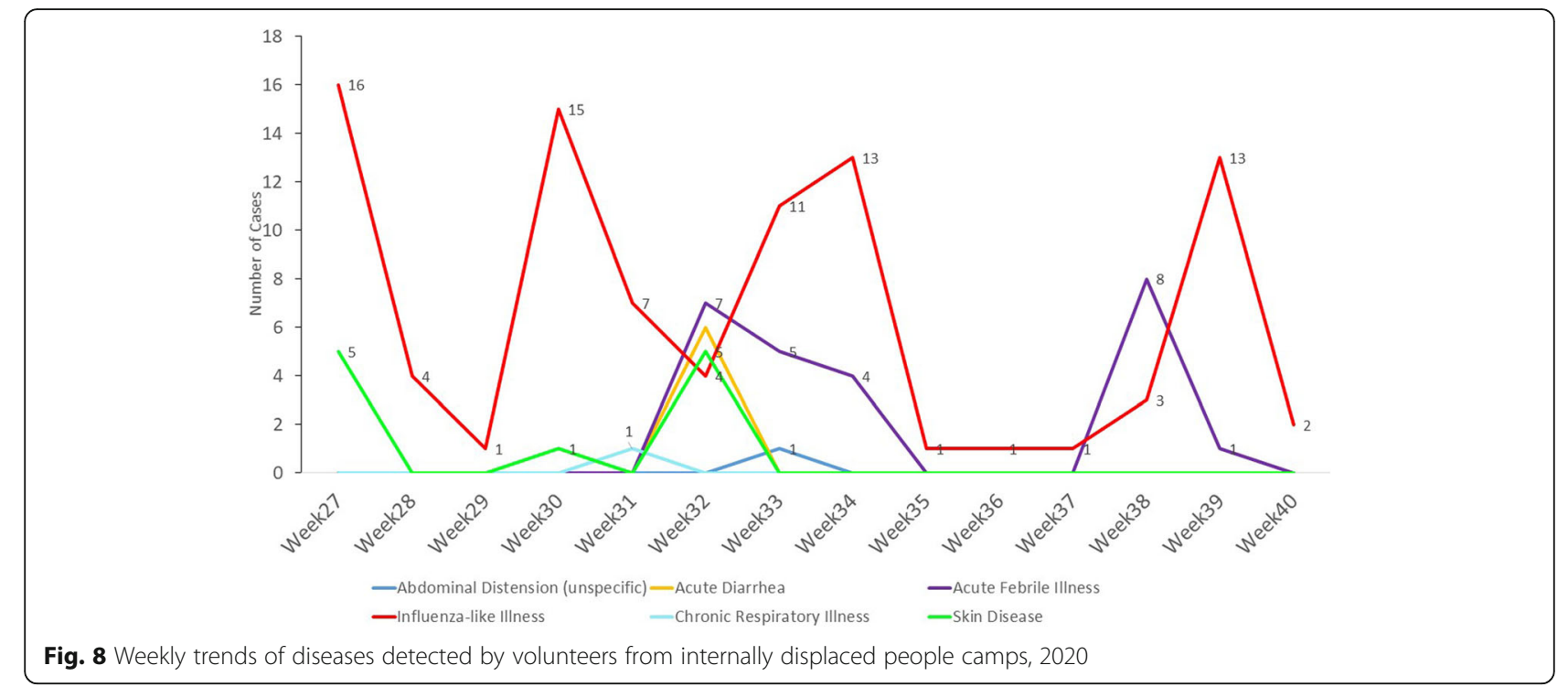

\section{Public health responses}

The cases of influenza-like illness in both IDP camps and urban areas did not trigger the deployment of RRTs and no specific public health actions were taken besides the referral of the cases to the health facilities for further investigations.

In the IDP camps, the cluster of febrile illness, acute diarrhoea and skin diseases were responded by the RRTs. The response to the cluster of acute febrile illness in Abyan governorate included the referral of the cases to the nearest health facility for further investigations, health education to the families on mosquito-borne disease prevention and removal of potential mosquito breeding sites around the houses. For the cluster of acute diarrhoea cases in Aden governorate, the RRTs provided oral rehydration solutions to the households as all the cases were mild, besides the chlorination of the drinking water and health education on prevention of diarrheal diseases. The cases of skin disease detected in Aden governorate were referred to the health facility for further investigation. Additionally, the RRTs provided health to the households on environmental cleaning, personal hygiene, waste disposal, treatment of water and others. No additional cases of the three diseases were reported in the camps after the public health actions were taken.

\section{Weekly narrative report findings}

The main challenges reported in Al-Mukalla city were instances of household refusal to interact with GCHVs owing to limited COVID-19 awareness, and the fear of GCHVs to participate in CBS owing to the lack of PPEs. Furthermore, other challenges reported in Hadramout were limited GCHV knowledge about other diseases and difficulties in performing door-to-door visits owing to frequent lockdowns. HFFPs from IDP camps and ICHVs reported insufficient health facilities near the camps for patient referral, difficulties in inter-camp movements owing to weather conditions, limited community health awareness, insufficient PPEs, and the lack of ambulances to transport cases to health facilities.

\section{Discussion}

The implementation of CBS in Yemen demonstrated to be more useful in IDP camps than in urban settings. In IDP camps, the system could detect suspected outbreaks and guided public health actions for control. However, it failed to detect outbreaks in urban settings. The reporting rate among GCHVs and HFFPs from Al-Mukalla City was also low, suggesting low acceptability of CBS among the staff. However, the acceptability among the communities remained unclear from our findings. At least one alert trigger was submitted by $58 \%(18 / 31)$ of ICHVs, compared to $18 \%(14 / 78)$ of GCHVs in $\mathrm{Al}$ Mukalla city. The low reporting rates of CBS in AlMukalla city may have been affected by low willingness of the GCHVs and HFFPs to perform the activities, low mentoring by the supervisors, and high refusal rates by the communities to provide the information. The higher reporting rate of CBS in the IDP camps was likely because a few households were assigned to each ICHV (220 per ICHV). IDP camp households likely trusted the ICHVs more because they resided in the same camp and were very well known. The average numbers of households per GCHV in Al-Mukalla city was 180. Those number suggests that when CBS was activated, the GCHVs were probably not well known by the communities and therefore were not received by households owing to a fear of stigma [1]. Moreover, the assignment of a high number of households per GCHV proved to be 
ineffective in Kenya owing to the limited time for interaction between volunteers and households [23]. During the Ebola virus disease (EVD) outbreak in Sierra Leone, where the population per district is similar to that in Yemen, CBS was successfully implemented because many GCHVs were assigned for each district, with more than 1000 volunteers per district. In Sierra Leone, CBS detected $30 \%(16 / 31)$ of the EVD cases, while $70 \%$ of the cases were detected through the regular surveillance system [14]. In addition, GCHVs in Al-Mukalla city probably had the same fear of interacting with people with suspected COVID-19 in activities such as the investigation of community deaths, as the other health workers and RRTs owing to the lack of PPEs, as documented in the beginning of the pandemic in Yemen [1]. Although PPEs were provided by UNICEF and CCCM partners, they were likely insufficient due to global shortage observed during the initial stages of COVID-19 pandemic [24]. Confidentiality issues during the field activities may also have contributed to fear of stigmatization and refusal by the communities in Al-Mukalla city. The GCHVs were oriented to not enter the houses as a precautionary measure. This may have led to fear of the households that neighbours and other people in the streets would hear their conversation with GCHVs. The implementation of CBS in urban areas such as AlMukalla city is usually a challenge, requiring better coordination and an extensive education of communities, as demonstrated in Kenya and Yemen during the implementation of integrated community case management program in 2017 [23, 25].

The variety of diseases alerts reported by ICHVs was also higher than those reported by GCHVs from AlMukalla city. While 14 GCHVs from Al-Mukalla city only detected alerts of influenza-like illness, 18 ICHVs detected five other syndromes, including suspected outbreaks of a febrile illness, acute diarrhoea, and skin disease, besides influenza-like illness. While GCHVs detected 49 alerts of influenza-like illness, the health facilities in the same area of CBS implementation reported 561 confirmed cases of COVID-19, including 224 deaths (case fatality ratio $=40 \%$ ). The high mortality of COVID19 in these areas indicates that the cases reached the health facility late and likely many cases remained in the houses undetected by CBS [1]. Additionally, 90\% $(n=92)$ of influenza-like illness alerts detected in the districts implementing CBS in IDP camps were reported by ICHVs, compared to $10 \%(n=10)$ of alerts detected through eDEWS during the same surveillance period. The number of people per household in IDP camps is usually higher than in host communities, and people in the IDP camps live in precarious conditions [11]. Therefore, different infectious disease outbreaks are usually anticipated among camp IDPs [26, 27]. Furthermore, the districts implementing CBS in IDP camps in Yemen were facing outbreaks of dengue fever and cholera. However, Al-Mukalla city was also facing an outbreak of dengue fever, and 284 alerts of acute febrile illness were reported through eDEWS during the CBS implementation period. Therefore, it would be expected alerts of febrile illness to be reported also by GCHVs. The early detection of suspected outbreaks of acute febrile illness, acute diarrhoea, and skin disease by the ICHVs allowed early deployment of RRTs, implementation of public health actions, and prevented the occurrence of additional cases. Owing to insufficient trainings and inadequate knowledge on other diseases, GCHVs from AllMukalla city reported only cases of influenza-like illness. ICHVs, despite their insufficient trainings on other diseases, were supervised by medical doctors, and few ICHVs were assigned for each supervisor. In Hadramout governorate, the GCHVs were supervised by nonclinicians who had insufficient clinical knowledge despite their public health background.

To allow for the identification of some challenges prior to CBS implementation, project feasibility and community acceptability should be assessed [6]. However, in Yemen, proper assessments were not performed because the project was implemented as part of an emergency response rather than as routine surveillance. The community and local authorities perceptions regarding CBS, reasons of low reporting of cases to the health facilities, proper calculation of resources and supplies needed, sustainability and other aspects should be considered before the implementation of CBS $[25,28]$.

The inadequate number of health facilities closer to camps for patient referral, difficult inter-camp movements owing to weather conditions, and lack of ambulances to transport the cases to the health facilities were some of the challenges reported by ICHVs. In both IDP camps and urban settings, no feedback was provided from laboratories and health facilities to CBS focal points. All suspected and confirmed cases were recorded in the generic line lists of routine surveillance, and the cases reported through CBS were not specified. The challenges reported in Yemen were previously documented during the implementation of the integrated community case management in 2017 and are similar to those in other developing countries that attempted CBS implementation [15, 25, 29]. The cost of setting set up a CBS system to support routine surveillance is usually huge, exceeding 1000,000 USD for the purchase of motorbikes, organisation of trainings, purchase of mobile phones and other items, excluding a monthly running costs that may exceed 100,000 USD in a country such as Sierra Leone [14]. Most of the required items, including mobile phones and computers, were not provided in Yemen, which was another probable reason for the 
inadequate reporting from GCHVs in Al-Mukalla city. However, the impact of CBS in Yemen, especially in IDP camps, was higher when matched with the funds used for its implementation that did not exceed 50,000 USD for 6 months. Limited funds available for CBS continuation is a very commonly reported challenge in other countries $[29,30]$.

This study had several potential limitations. First, there were no available previous studies documenting CBS in Yemen and the studies from other countries in the region were also few. Therefore, we could not compare our findings with those from other Yemeni and Eastern Mediterranean region studies. Second, some key indicators of CBS such as question refusal rates in the communities, timeliness of data reporting, and quantity of PPEs provided to the volunteers and focal points, were not properly documented. Therefore, we were unable to assess some of the CBS attributes requiring these indicators. Third, the information on the number of households in IDP camps was not accurate because people were constantly arriving and leaving the camps. Therefore, some numbers observed by ICHVs did not reflect those reported in RDT system. Thus, we adjusted the numbers in our report by matching with the numbers provided by the ICHVs. Despite these limitations, our findings will be useful for a further expansion of the project in the future.

\section{Conclusions and future perspectives}

CBS in Yemen demonstrated to be an extremely useful tool to detect outbreaks of respiratory and other diseases in IDP camps, as it led to early detection and implementation of public health actions which prevented the occurrence of further cases. CBS implementation in the early stage of the COVID-19 pandemic, when little was known about the disease, did not yield expected results in general communities in urban areas. The system failed to detect suspected COVID-19 cases and other diseases in Al-Mukalla city despite the ongoing outbreaks in the same location reported through eDEWS. The ability of the staff, including the detection of diseases in the communities was better among volunteers supervised by clinicians than among those supervised with staff without a clinical background. The acceptability of CBS among the staff was higher in IDP camps compared to the urban settings. The acceptability among the communities was unclear from our findings. In Yemen, as in other countries, feasibility and acceptability studies should be conducted few months before CBS expansion in urban communities. Due to the ongoing complex emergency and COVID-19 pandemic, CBS should be expanded in IDP camps in Yemen, through creation of suspected COVID-19 and other diseases outbreaks reporting sites. We also recommend the volunteers to be supervised by staff with clinical background; development of country specific CBS guidelines with community case definitions for other diseases with a risk for outbreak in Yemen; and the strengthening of the link between CBS and routine surveillance systems through feedbacks to HFFPs and community volunteers on the outcome of patients and laboratory results.

\begin{abstract}
Abbreviations
C4D: Communication for development; CBS: Community-based surveillance; CCCM: Camp Coordination and Camp Management; COVID-19: Coronavirus disease - 19; eDEWS: Electronic disease Early Warning System; EVD: Ebola virus disease; GCHV: General Community health volunteers;

GHO: Governorate Health Office; HFFP: Health facility focal points; ICHV: IDP community health volunteer; IDP: Internally displaced people; IOM: International Organization for Migration; MOPHP: Ministry of Public Health and Population; PPE: Personal protective equipment; RDT: Rapid displacement tracking; RRT: Rapid Response Team; UNICEF: United Nations Children's Fund; WHO: World Health Organization
\end{abstract}

\section{Supplementary Information}

The online version contains supplementary material available at https://doi. org/10.1186/s13031-021-00394-1.

Additional file 1. Alert trigger form in English translation.

Additional file 2. Alert trigger form in original Arabic version.

Additional file 3. Weekly aggregated form.

\section{Acknowledgements}

We thank the United Nations Children's Fund for provision of community volunteers in Hadramout governorate, production, and printing of

Community-based surveillance brochures to be used by the volunteers. We also thank the United Nations High Commissioner for Refugees for facilitating the selection of volunteers of IDP camps, and the Camp Coordination and Camp Management partners, namely Danish Refugee Council, Generations Without Qat, Agency for Technical Cooperation and Development, International Organization for Migration, Norwegian Refugee Council, and Executive Unit for IDPs for selecting the volunteers from IDP camps and refugees and for facilitating the trainings.

\section{Disclaimer}

The findings and conclusions in this report are those of the authors and do not necessarily represent the views of the World Health Organization and Ministry of Public Health and Population of Yemen.

\section{Authors' contributions}

MSOB was a major contributor in conception and design, revised the manuscript critically for important intellectual content, analysed and interpreted the data. JDN drafted the manuscript, analysed, and interpreted the data. AAA contributed to analysis and interpretation of data, revised the manuscript critically for important intellectual content. NSBA, was a major contributor in acquisition of data, contributed to analysis and interpretation of the data. MFK, contributed acquisition, analysis, and interpretation of data, revised the manuscript critically for important intellectual content. NM, contributed to conception, resources mobilization, supervision, revised the manuscript critically for important intellectual content. AM contributed to conception, resources mobilization, supervision and revised the manuscript critically for important intellectual content. All authors read and approved the final manuscript.

\section{Funding}

The implementation of CBS was funded by Kuwait Fund. The funders had no role in the design of the study and collection, analysis, and interpretation of data and in writing the manuscript. 


\section{Availability of data and materials}

All data generated or analysed during this study are included in this published article.

\section{Declarations}

\section{Ethics approval and consent to participate}

The project was implemented in response to the COVID-19 public health emergency and not as a research. Therefore, no ethical approval was required. The implementation of the project was endorsed by the MOPHP and all the partner organizations that were part of it. Reports were presented in aggregated summaries, and the details of individual cases and the IDP camp names were not disclosed.

\section{Consent for publication}

Not applicable.

\section{Competing interests}

The authors declare that they have no competing interests

\section{Author details}

${ }^{1}$ World Health Organization, Sana'a, Yemen. ${ }^{2}$ Ministry of Public Health and Population, Aden, Yemen.

Received: 22 December 2020 Accepted: 29 June 2021

Published online: 05 July 2021

\section{References}

1. Al-waleedi AA, Naiene JD, Thabet AAK, Dandarawe A, Salem H, Mohammed $\mathrm{N}$, et al. The first 2 months of the SARS-CoV-2 epidemic in Yemen: analysis of the surveillance data. PLoS One. 2020;15(10):e0241260. https://doi.org/1 0.1371/journal.pone.0241260

2. Devi S. World report fears of "highly catastrophic" COVID-19 spread in Yemen. Lancet. 2020;395(10238):1683. https://doi.org/10.1016/S0140-6736(2 0)31235-6.

3. Dureab F, Ahmed K, Beiersmann C, Standley CJ, Alwaleedi A, Jahn A. Assessment of electronic disease early warning system for improved disease surveillance and outbreak response in Yemen. BMC Public Health. 2020; 20(1):1422. https://doi.org/10.1186/s12889-020-09460-4.

4. Spiegel $P$, Ratnayake $R$, Hellman $N$, Ververs $M$, Ngwa M, Wise PH, et al. Responding to epidemics in large-scale humanitarian crises : a case study of the cholera response in Yemen, 2016-2018. BMJ Glob Health. 2019;4(4): e001709. https://doi.org/10.1136/bmjgh-2019-001709.

5. Kitala PM, Mcdermott JJ, Kyule MN, Gathuma JM. Community-based active surveillance for rabies in Machakos District, Kenya. Prev Vet Med. 2000;44(12):73-85. https://doi.org/10.1016/S0167-5877(99)00114-2.

6. Abass KM, Werf TS, Phillips RO, Sarfo FS, Abotsi J, Mireku SO, et al. Short report: Buruli ulcer control in a highly endemic district in Ghana: role of community-based surveillance volunteers. Am J Trop Med Hyg. 2015;92(1): 115-7. https://doi.org/10.4269/ajtmh.14-0405.

7. Weah VD, Doedeh JS, Wiah SQ, Nyema E, Lombeh S, Naiene J. Enhancing ebola virus disease surveillance and prevention in counties without confirmed cases in rural Liberia: experiences from Sinoe county during the flare-up in Monrovia, April to June, 2016. PLoS Curr. 2017;9:9.

8. Nagbe T, Naiene JD, Rude JM, Mahmoud N, Kromah M, Sesay J, et al. The implementation of integrated disease surveillance and response in Liberia after Ebola virus disease outbreak 2015-2017. Pan Afr Med J. 2019;33:1-8.

9. Garber K, Fox C, Abdalla M, Tatem A, Qirbi N, Lloyd-braff L, et al. Estimating access to health care in Yemen, a complex humanitarian emergency setting : a descriptive applied geospatial analysis. Lancet Glob Health. 2020; 8(11):e1435-43. https://doi.org/10.1016/S2214-109X(20)30359-4.

10. Kuehne A, Keating P, Polonsky J, Haskew C, Schenkel K, le Polain de Waroux $\mathrm{O}$, et al. Event-based surveillance at health facility and community level in low-income and middle-income countries: a systematic review. BMJ Glob Health. 2019;4(6):e001878. https://doi.org/10.1136/bmjgh-2019-001878.

11. Duclos D, Palmer B. COVID-19 and forced displacement in the Middle East and East Africa. Soc Sci Humanit action Platf. 2020;1:1-27.

12. Ekezie W, Adaji EE, Murray RL. Essential healthcare services provided to conflict-affected internally displaced populations in low and middle-income countries : a systematic review. Tabriz Univ Med Sci. 2020;10:24-37.
13. IOM Yemen. IOM Yemen rapid displacement tracking (RDT). 2020. https:// dtm.iom.int/reports/yemen. Accessed 16 Jun 2021.

14. Ratnayake R, Crowe SJ, Jasperse J, Privette G, Stone E, Miller L, et al. Assessment of community event - based surveillance for Ebola. Emerg Infect Dis. 2016;22(8):1431-7. https://doi.org/10.3201/eid2208.160205.

15. Lado M, Mackoy S, Steve B, Rumunu J. Evaluation of community-based surveillance for Guinea worm, South Sudan, 2006. SSMJ. 2012;5:72-4.

16. Id G, Acharya P. Community-based surveillance: a scoping review. PLoS One. 2019;14(4):e0215278. https://doi.org/10.1371/journal.pone.0215278.

17. Al-mekhla HM. Yemen in a time of cholera: current situation and challenges. Am J Trop Med Hyg. 2018;98(6):1558-62. https://doi.org/10.4269/ajtmh.170811.

18. Ba A. Coverage of and barriers to routine child vaccination in Mukalla district, Hadramout governorate, Yemen. EMHJ. 2020;16:223-7.

19. Khalidi O. The Arabs of Hadramawt in Hyderabad. Mediaev Deccan Hist Bombay; 1996. p. 52-75. Commmoerat (Bombay: Popular Prakashan)

20. Central Statistical Organisation of Yemen. Population, housing and establishment census 2004 first report. 2007.

21. World Health Organization. A guide for establishing community-based surveillance. 2014.

22. Centers for Disease Control and Prevention. Updated guidelines for evaluating public health surveillance systems: recommendations from the guide-lines working group. MMWR. 2001;50(No. RR-13):[inclusive page numbers].

23. Aseyo RE, Mumma J, Scott K, Nelima D, Davis E, Baker KK, et al. Realities and experiences of community health volunteers as agents for behaviour change: evidence from an informal urban settlement in Kisumu. Kenya Hum Resour Health. 2018;16(1):53. https://doi.org/10.1186/s12960-018-0318-4.

24. Ranney ML, Griffeth V, Jha AK. Critical supply shortages-the need for ventilators and personal protective equipment during the Covid-19 pandemic. N Engl J Med. 2020;382(18):e41. https://doi.org/10.1056/NEJMp2 006141.

25. Miller NP, Zunong N, Abdulrahman TA, Alqadasi M, Ashraf S. Implementing integrated community case management during conflict in Yemen. J Glob Health. 2020;10:1-10.

26. Ekezie W, et al. An audit of healthcare provision in internally displaced population camps in Nigeria. J Public Health. 2019;41.3:583-92.

27. Desai AN, Ramatowski JW, Marano N, Madoff LC, Lassmann B. Infectious disease outbreaks among forcibly displaced persons: an analysis of ProMED reports 1996-2016. Confl Heal. 2020;14(1):49. https://doi.org/10.1186/s13031020-00295-9.

28. Mahmood SS, Rasheed S, Chowdhury AH. Hossain A, Feasibility, acceptability and initial outcome of implementing community scorecard to monitor community level public health facilities : experience from rural Bangladesh. Int J Equity Health. 2020;6:1-11.

29. Visser L, Directorate RH, Directorate RH, Hospital HF. The role of communitybased surveillance in health outcomes measurement. Ghana Med J. 2006;40: 26-30.

30. Guessan SN, Attiey HB, Ndiaye S, Diarrassouba M, Shamamba L, Traoré Y, et al. Community-based surveillance: a pilot experiment in the Kabadougou-Bafing-Folon health region in Côte d'Ivoire. JIEPH. 2019;2:11.

\section{Publisher's Note}

Springer Nature remains neutral with regard to jurisdictional claims in published maps and institutional affiliations.

Ready to submit your research? Choose BMC and benefit from:

- fast, convenient online submission

- thorough peer review by experienced researchers in your field

- rapid publication on acceptance

- support for research data, including large and complex data types

- gold Open Access which fosters wider collaboration and increased citations

- maximum visibility for your research: over $100 \mathrm{M}$ website views per year

At BMC, research is always in progress.

Learn more biomedcentral.com/submissions 